\title{
Random Simulation Study on Flood Process of Flood Control Engineering System in Nanning
}

\author{
Rong-yong Ma1,a, Yi Dü,b and Jia-li Lin ${ }^{3, c}$ \\ ${ }^{1}$ College of Civil Engineering and Architecture, Guangxi University, China \\ ${ }^{2}$ College of Civil Engineering and Architecture, Guangxi University, China \\ ${ }^{3}$ Guangxi Key Laboratory of Disaster Prevention and Engineering Safety, Guangxi, China \\ amry57@gxu.edu.cn, bduyi19930922@163.com, ‘563435554@qq.com
}

Keywords: Flood control engineering system; Flood random simulation; SAR(1) model; Characteristic parameter

Abstract: In order to better carry out the research on the flood control capacity of the flood control engineering system in Nanning, using the SAR(1) model to simulate various 50 thousands of flood process of Baise reservoir inflow and Baise-Nanning interval, and analyze the independence and applicability of the model. The independent autocorrelation coefficient and the autocorrelation analysis method are used to test the independence of the random term of various sections of the model. The results show that assumption that residual series of the model is independent are reasonable. By comparing the characteristic parameters of each section of the simulated and measured flood process, it is found that their coincidence degree is high and the simulated flood sequence well maintains the statistical characteristics of the measured flood, which fully shows that the SAR(1) model is suitable for random simulation of flood in Baise reservoir inflow and Baise-Nanning interval.

\section{Introduction}

The flood process line is an important data for hydrological analysis. It is generally necessary to have a sufficient amounts of flood process lines to carry out flood control calculations. However, due to the limited data of hydrological station observation, the data length of the general flood process line is insufficient, and it is difficult to carry out engineering analysis and calculation. Therefore, the establishment of random simulation model of hydrological process has become one of the important contents of hydrological process analysis. After a random simulation of the flood process is proposed as a new way of flood control safety design, a number of studies have been carried out at home and abroad, and a variety of flood random simulation models have been generated ${ }^{[1]}$, such as autoregressive model, typical solution model, nonlinear model and so on. In recent years, emerging nonparametric models ${ }^{[2]}$, wavelet analysis ${ }^{[3]}$, random simulation based on Copula function ${ }^{[4-5]}$ and other methods have been applied to the field of random flood simulation, which greatly enriched the theory and method of flood random simulation.

Thereinto, hydrological simulation model and method of the regressive sort is relative mature, can be applied in large and medium-sized watershed, has a strong applicability. Therefore, this study select the seasonal first order autoregressive model ${ }^{[6]}$, which can reflect the seasonal characteristics of floods variation among regression models. 


\section{Model introduction}

\section{Model calculation method and thinking ${ }^{[7]}$}

Assume that the flood process series $Q_{t, w}$ is expressed by the matrix:

$$
\left\{Q_{t, w}\right\}_{n \times m}=\left[\begin{array}{rrrlr}
Q_{1,1} & Q_{1,2} & Q_{1,3} & \mathrm{~L} & Q_{1, m} \\
Q_{2,1} & Q_{2,2} & Q_{2,3} & \mathrm{~L} & Q_{2, m} \\
\mathrm{M} & \mathrm{M} & \mathrm{M} & \mathrm{M} & \mathrm{M} \\
Q_{t, 1} & Q_{t, 2} & Q_{t, 3} & \ldots & Q_{t, m} \\
\mathrm{M} & \mathrm{M} & \mathrm{M} & \mathrm{M} & \mathrm{M} \\
Q_{n, 1} & Q_{n, 2} & Q_{n, 3} & \ldots & Q_{n, m}
\end{array}\right]
$$

Thereinto, $t=1,2, \mathrm{~L}, n, n$ is the number of years; $w=1,2, \mathrm{~L}, m, m$ is the number of sections.

The seasonal first order autoregressive model SAR(1) expressed in the original series $Q_{t, w}$ can be written as:

$$
Q_{t, w}=\varphi_{1, \mathrm{w}} Q_{t, w-1}+\varepsilon_{t, w}
$$

Thereinto, $\varphi_{1, \mathrm{w}}$ is the autoregressive coefficient of the section ${ }_{w} ; \varepsilon_{t, w}$ is the random number of the normal distribution.

To eliminate the seasonal effects of mean $\mu_{w}$ and variance $\sigma_{\mathrm{w}}{ }^{2}$, the original series $Q_{t, w}$ should be standardized:

$$
Y_{t, w}=\frac{Q_{t, w}-\mu_{w}}{S_{w}}
$$

Thereinto, $\mu_{w}, S_{w}$ are the mean and mean variance of the original section $w$ respectively.

And then the standardized series $Y_{t, w}$ becomes the standard normal series by $\mathrm{W}-\mathrm{H}$ inverse transformation :

$$
Z_{t, w}=\frac{6}{C_{s, \mathrm{w}}}\left[\left(\frac{C_{s, w}}{2} Y_{t, w}+1\right)^{\frac{1}{3}}-1\right]+\frac{C_{s, w}}{6}
$$

Thereinto, $C_{s, w}$ is the skew coefficient of the original series of intersection $w$.

After the original series is standardized and normalized, the SAR(1) model established for the standard normalization series is:

$$
Z_{t, w}=\rho_{1, \mathrm{w}} Z_{t, w-1}+\xi_{t, w}
$$

Thereinto, $\rho_{1, \mathrm{w}}$ is the autoregressive coefficient, which is estimated by the first-order autocorrelation coefficient of the corresponding section,that is

$$
\rho_{1, \mathrm{w}}=\mathrm{r}_{1, \mathrm{w}}
$$

$\xi_{t, w}$ is an independent random variable whose mean is 0 and variance is $\sigma_{\xi, w}^{2}$.

$$
\sigma_{\xi, w}^{2}=\sqrt{1-r_{1, \mathrm{w}}^{2}}
$$


Therefore:

$$
Z_{t, w}=r_{1, \mathrm{w}} Z_{t, w-1}+\sqrt{1-r_{1, \mathrm{w}}^{2}} \varepsilon_{t, w}
$$

Finally, by the inverse transformation of the standardization and normalization, all $Z_{t, w}$ are conversed into a simulated flood process $Q_{t, w}$ :

$$
\begin{gathered}
Y_{t, w}=\left(\frac{2}{C_{s, w}}\right)\left(1+\frac{Z_{t, w} C_{s, w}}{6}-\frac{C_{s, w}{ }^{2}}{36}\right)^{3}-\frac{2}{C_{s, w}} \\
Q_{t, w}=\mu_{w}+Y_{t, w} S_{w}
\end{gathered}
$$

Formula (9) and (10) are the seasonal first-order autoregressive SAR(1) models finally obtained.

\section{Analysis of model residual feature and applicability analysis}

\section{Comprehensive autocorrelation coefficient test}

(1)According to the established random simulation model, the random term $\varepsilon_{t}$ of the sample series is obtained.

$$
\varepsilon_{t}=\left(Z_{t, w}-r_{1, \mathrm{w}} Z_{t, w-1}\right) / \sqrt{1-r_{1, \mathrm{w}}^{2}}
$$

(2) The autocorrelation coefficients $(k=1,2, \mathrm{~L}, m)$ are calculated according to the series of random items $\varepsilon_{t}$;

$$
r_{k}=\frac{\sum_{t=1}^{n-k}\left(x_{t+k}-\bar{x}\right)\left(x_{t}-\bar{x}\right)}{\sum_{t=1}^{n}\left(x_{t}-\bar{x}\right)^{2}}
$$

Thereinto, for value of m: when $n>50, m<n / 4$; when $n<50, m=n / 4$ or $m=n-10$.

(3)Construct statistic

$$
Q=n \sum_{k=1}^{m} r_{k, \varepsilon}^{2}
$$

If $\varepsilon_{t}$ is independent random series, $Q$ gradually obeys $\chi^{2}$ distribution whose degree of freedom is $\mathrm{m}-\mathrm{p}-\mathrm{q}$;

(4) Given a significant level of $\alpha$, obtain $\chi_{\alpha}{ }^{2}$ by checking $\chi^{2}$ distribution table, if $Q \leq \chi_{\alpha}{ }^{2}$ it can be judged that $\varepsilon_{t}$ is independent, and vice versa is not independent.

\section{Autocorrelation analysis}

First, reversely calculate random item $\varepsilon_{t}$ series by the model, calculate the autocorrelation coefficient $r_{k, \varepsilon}$, and then calculate the upper and lower allowable limits whose tolerance is $95 \%$ by the formula. The upper and lower tolerance limits and autocorrelation coefficients are plotted on the 
same graph to determine whether the autocorrelation coefficient falls in the upper and lower limits. If yes, it indicates that $\varepsilon_{t}$ is independent , and vice versa is not independent. Thereinto, the formula for calculating the allowable limit is:

$$
r_{k}(\alpha=5 \%)=\frac{-1 \pm 1.96 \sqrt{n-k-1}}{n-k}
$$

Applicability analysis mainly analyzes whether the results the model simulated maintain statistical characteristics of the measured series. If the statistical parameters of the simulation results have little difference with the corresponding statistical parameters of the measured series, the model results can be regarded as inferred totality.

\section{Flood simulation}

The SAR(1) model is used to simulate the flood of Baise reservoir and Baise-Nanning interval, and make residual independence test and suitability analysis of the model, due to space restrictions, the following takes simulation of inflow flood of Baise reservoir only as an example to introduce.

In the collected flood data of 46 years in Baise reservoir, every year select flood process whose duration is $7 \mathrm{~d}$, take $3 \mathrm{~h}$ for a section and divide it into 56 sections. There are exceptionally large flood year, the general medium flood year and small flood years in the selected flood process data of Baise reservoir. So the data is a good representative. MATLAB software programming is used to get 50,000 flood process of Baise reservoir.

\section{Simulation of flood simulation model of Baise reservoir}

The flood simulation of Baise reservoir is carried out by the way about sections. First obtain the random term from the model, and then calculate the autocorrelation coefficient whose delay time is $k(k=1,2, \mathrm{~L}, m)$. Flood simulation Baise reservoir, due to the number of sections greater than 50, takes $m=13$. The results are shown in Table 1 and Table 2 .

Table 1 Randomness of baise reservoir flood simulation model

\begin{tabular}{cccccccc}
\hline section & $\varepsilon_{t}$ & section & $\varepsilon_{t}$ & section & $\varepsilon_{t}$ & section & $\varepsilon_{t}$ \\
\hline 1 & 1.16160 & 15 & -0.02827 & 29 & -0.24867 & 43 & -0.90042 \\
2 & 0.71557 & 16 & -1.01840 & 30 & -0.84084 & 44 & -0.09350 \\
3 & 0.47132 & 17 & 1.97420 & 31 & 0.42810 & 45 & -0.93018 \\
4 & -0.52042 & 18 & 1.01740 & 32 & -0.01269 & 46 & -0.79567 \\
5 & -0.09795 & 19 & -0.57583 & 33 & 1.07210 & 47 & 1.14530 \\
6 & -0.15945 & 20 & 1.28810 & 34 & 0.87343 & 48 & -0.28157 \\
7 & 0.44658 & 21 & 0.17754 & 35 & -1.99530 & 49 & -0.04258 \\
8 & 0.37822 & 22 & -0.34276 & 36 & 0.17735 & 50 & 0.23605 \\
9 & -0.39596 & 23 & -1.05830 & 37 & -0.05637 & 51 & -0.10833 \\
10 & -0.23490 & 24 & -1.67300 & 38 & -1.92990 & 52 & 0.40390 \\
11 & 0.62386 & 25 & -0.91167 & 39 & 0.28801 & 53 & -0.44096 \\
12 & -0.38048 & 26 & -0.87178 & 40 & 1.00560 & 54 & 1.34790 \\
13 & 1.05300 & 27 & -0.49123 & 41 & -1.04060 & 55 & 1.03720 \\
14 & -0.76408 & 28 & -0.39264 & 42 & 0.77340 & 56 & -0.51616 \\
\hline
\end{tabular}


Table 2 Autocorrelation coefficient of randomness

\begin{tabular}{cccc}
\hline Lag time $(\mathrm{k})$ & $\begin{array}{c}\text { Autocorrelation } \\
\text { coefficient }\end{array}$ & Lag time $(\mathrm{k})$ & $\begin{array}{c}\text { Autocorrelation } \\
\text { coefficient }\end{array}$ \\
\hline 1 & -0.02352 & 8 & 0.03188 \\
2 & 0.02065 & 9 & -0.18860 \\
3 & 0.16418 & 10 & 0.03826 \\
4 & -0.17111 & 11 & 0.04949 \\
5 & 0.01035 & 12 & -0.05896 \\
6 & -0.08547 & 13 & 0.01651 \\
7 & -0.02864 & & \\
\hline
\end{tabular}

(1) Comprehensive autocorrelation coefficient test

By calculation, obtain that statistic $Q=6.143$. Take the significance level $\alpha=0.05$. Get that $\chi_{\alpha}^{2}=$ 21.0261 by checking $\chi^{2}$ distribution table. By comparison, $Q<\chi_{\alpha}^{2}$, it indicates that the model is independent and can be used to describe the flood characteristics.

(2) Autocorrelation analysis

When using autocorrelation analysis to test, it is necessary to determine whether the autocorrelation coefficient falls between $95 \%$ upper and lower allowable limits. If so, it can be judged that is independent. Obtain the autocorrelation coefficient by calculation, 95\% tolerance of the upper and lower tolerance limit, the results are shown in Table 3. As can be seen from Fig. 1, the autocorrelation coefficient falls within the allowable limit, so the model passes the independence test.

Table 3 The flood simulation model residual independence test of Baise reservoir

\begin{tabular}{cccc}
\hline \multirow{2}{*}{$\begin{array}{c}\text { Lag } \\
\text { time }(\mathrm{k})\end{array}$} & \multicolumn{3}{c}{ Autocorrelation coefficient and allowable limit } \\
\cline { 2 - 4 } & Upper allowable limit & $\begin{array}{c}\text { Autocorrelation } \\
\text { coefficient }\end{array}$ & Lower allowable limit \\
\hline 1 & 0.2437 & -0.02352 & -0.2801 \\
2 & 0.2457 & 0.020648 & -0.2828 \\
3 & 0.2478 & 0.16418 & -0.2855 \\
4 & 0.2499 & -0.17111 & -0.2884 \\
5 & 0.2521 & 0.010352 & -0.2914 \\
6 & 0.2544 & -0.08547 & -0.2944 \\
7 & 0.2567 & -0.02864 & -0.2975 \\
8 & 0.2591 & 0.03188 & -0.3008 \\
9 & 0.2616 & -0.1886 & -0.3041 \\
10 & 0.2641 & 0.038257 & -0.3076 \\
11 & 0.2667 & 0.049494 & -0.3111 \\
12 & 0.2694 & -0.05896 & -0.3148 \\
13 & 0.2721 & 0.016509 & -0.3187 \\
\hline
\end{tabular}




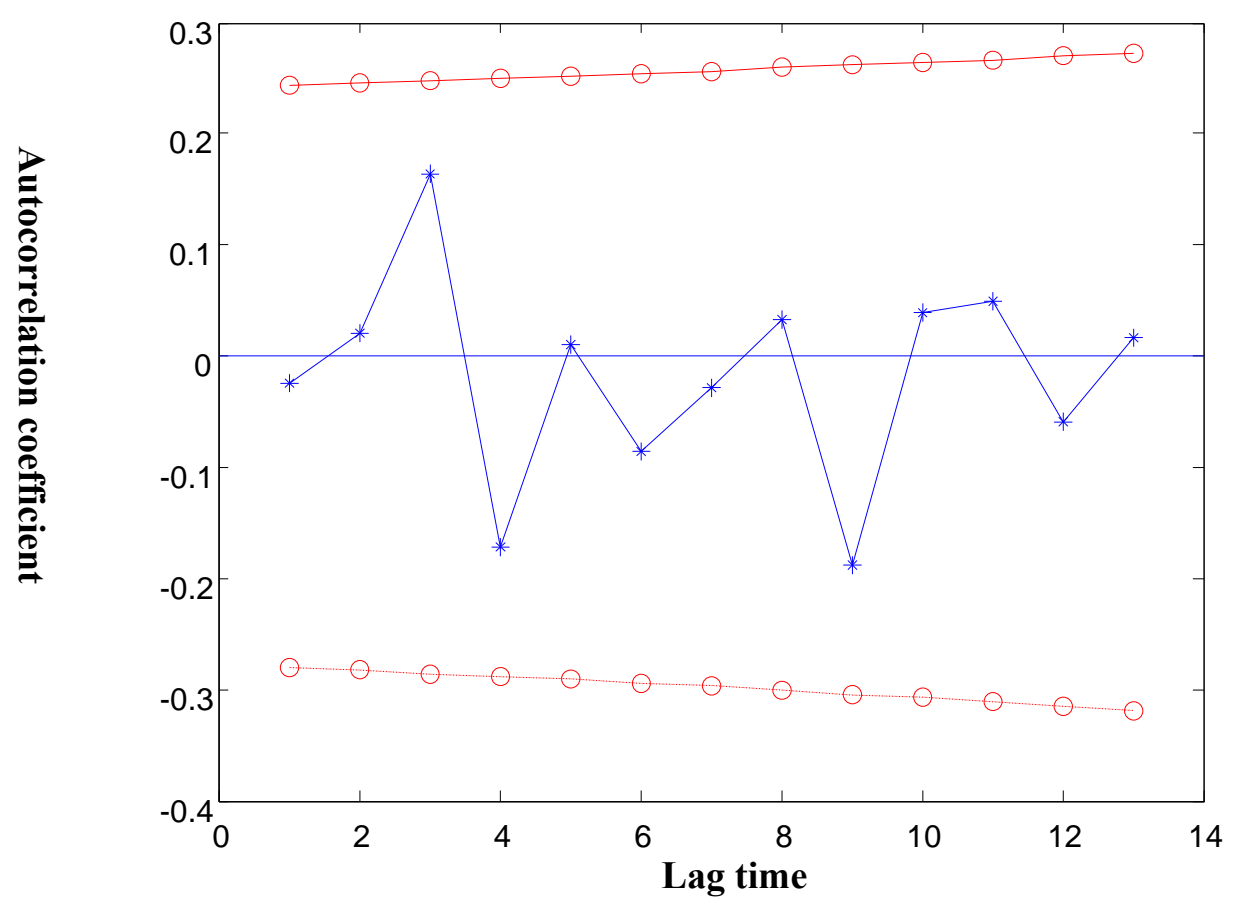

Fig.1 The flood simulation model of random item autocorrelation coefficient figure of Baise reservoir

\section{Applicability Analysis of Flood Simulation Results of Baise Reservoir}

In order to test whether the flood generated by the simulation has maintained the statistical characteristics of the measured floods or represent the measured samples well. Calculate the characteristic parameters of various sections of the flood process series and compare them with the measured flood series. 
Table 4 comparison of simulated and measured parameters of Baise reservoir

\begin{tabular}{|c|c|c|c|c|c|c|c|c|c|c|c|c|}
\hline \multirow{2}{*}{ section } & \multicolumn{3}{|c|}{ mean } & \multicolumn{3}{|c|}{ mean square error } & \multicolumn{3}{|c|}{ coefficient of variation } & \multicolumn{3}{|c|}{ coefficient of skewness } \\
\hline & measured & simulation & $\begin{array}{l}\text { relative } \\
\text { error(\%) }\end{array}$ & measured & simulation & $\begin{array}{l}\text { relative } \\
\text { error(\%) }\end{array}$ & measured & simulation & $\begin{array}{l}\text { relative } \\
\text { error(\%) }\end{array}$ & measured & simulation & $\begin{array}{l}\text { relative } \\
\text { error(\%) }\end{array}$ \\
\hline 1 & 970.72 & 972.38 & 0.171 & 402.65 & 405.19 & 0.631 & 0.415 & 0.417 & 0.458 & 0.724 & 0.739 & 2.207 \\
\hline 2 & 1005.30 & 1007.10 & 0.179 & 417.05 & 419.68 & 0.631 & 0.415 & 0.417 & 0.458 & 0.725 & 0.741 & 2.205 \\
\hline 3 & 1022.70 & 1024.50 & 0.176 & 424.25 & 426.93 & 0.632 & 0.415 & 0.417 & 0.458 & 0.724 & 0.740 & 2.198 \\
\hline 4 & 1040.00 & 1041.80 & 0.173 & 431.46 & 434.18 & 0.630 & 0.415 & 0.417 & 0.458 & 0.725 & 0.741 & 2.193 \\
\hline 5 & 1057.40 & 1059.20 & 0.170 & 438.59 & 441.35 & 0.629 & 0.415 & 0.417 & 0.458 & 0.724 & 0.740 & 2.195 \\
\hline 6 & 1074.70 & 1076.50 & 0.167 & 445.80 & 448.61 & 0.630 & 0.415 & 0.417 & 0.458 & 0.724 & 0.739 & 2.191 \\
\hline 7 & 1092.00 & 1093.90 & 0.174 & 452.96 & 455.82 & 0.631 & 0.415 & 0.417 & 0.458 & 0.725 & 0.741 & 2.186 \\
\hline 8 & 1109.30 & 1111.20 & 0.171 & 460.19 & 463.09 & 0.630 & 0.415 & 0.417 & 0.456 & 0.724 & 0.740 & 2.187 \\
\hline 9 & 1123.60 & 1125.30 & 0.151 & 453.52 & 456.29 & 0.611 & 0.404 & 0.405 & 0.461 & 0.724 & 0.739 & 1.997 \\
\hline 10 & 1137.90 & 1139.70 & 0.158 & 448.72 & 451.36 & 0.588 & 0.394 & 0.396 & 0.423 & 0.729 & 0.742 & 1.796 \\
\hline 11 & 1152.10 & 1153.70 & 0.139 & 445.82 & 448.43 & 0.585 & 0.387 & 0.389 & 0.442 & 0.740 & 0.753 & 1.789 \\
\hline 12 & 1166.50 & 1168.30 & 0.154 & 444.97 & 447.38 & 0.542 & 0.381 & 0.383 & 0.388 & 0.758 & 0.770 & 1.599 \\
\hline 13 & 1180.40 & 1182.30 & 0.161 & 445.95 & 448.53 & 0.579 & 0.378 & 0.379 & 0.418 & 0.782 & 0.793 & 1.475 \\
\hline 14 & 1194.70 & 1196.50 & 0.151 & 449.03 & 451.60 & 0.572 & 0.376 & 0.377 & 0.426 & 0.811 & 0.823 & 1.462 \\
\hline
\end{tabular}




\begin{tabular}{|c|c|c|c|c|c|c|c|c|c|c|c|c|}
\hline \multirow[b]{2}{*}{ section } & \multicolumn{3}{|c|}{ mean } & \multicolumn{3}{|c|}{ mean square error } & \multicolumn{3}{|c|}{ coefficient of variation } & \multicolumn{3}{|c|}{ coefficient of skewness } \\
\hline & measured & simulation & $\begin{array}{l}\text { relative } \\
\text { error(\%) }\end{array}$ & measured & simulation & $\begin{array}{l}\text { relative } \\
\text { error(\%) }\end{array}$ & measured & simulation & $\begin{array}{l}\text { relative } \\
\text { error(\%) }\end{array}$ & measured & simulation & $\begin{array}{c}\text { relative } \\
\text { error }(\%)\end{array}$ \\
\hline 15 & 1208.90 & 1210.60 & 0.141 & 453.89 & 456.34 & 0.540 & 0.375 & 0.377 & 0.405 & 0.846 & 0.857 & 1.305 \\
\hline 16 & 1223.10 & 1224.60 & 0.123 & 460.73 & 462.81 & 0.451 & 0.377 & 0.378 & 0.329 & 0.883 & 0.889 & 0.655 \\
\hline 17 & 1286.20 & 1287.80 & 0.124 & 485.14 & 486.84 & 0.350 & 0.377 & 0.378 & 0.225 & 0.718 & 0.723 & 0.667 \\
\hline 18 & 1349.20 & 1351.00 & 0.133 & 522.93 & 524.78 & 0.354 & 0.388 & 0.388 & 0.217 & 0.664 & 0.669 & 0.789 \\
\hline 19 & 1412.30 & 1414.10 & 0.127 & 571.59 & 573.71 & 0.371 & 0.405 & 0.406 & 0.240 & 0.723 & 0.730 & 1.015 \\
\hline 20 & 1475.50 & 1478.10 & 0.176 & 628.39 & 631.52 & 0.498 & 0.426 & 0.427 & 0.322 & 0.853 & 0.864 & 1.319 \\
\hline 21 & 1538.40 & 1541.30 & 0.189 & 691.55 & 695.57 & 0.581 & 0.450 & 0.451 & 0.392 & 1.011 & 1.027 & 1.572 \\
\hline 22 & 1601.40 & 1604.50 & 0.194 & 759.54 & 764.11 & 0.602 & 0.474 & 0.476 & 0.411 & 1.172 & 1.194 & 1.868 \\
\hline 23 & 1664.50 & 1667.80 & 0.198 & 830.87 & 836.10 & 0.629 & 0.499 & 0.501 & 0.433 & 1.321 & 1.351 & 2.233 \\
\hline 24 & 1727.40 & 1731.20 & 0.220 & 905.04 & 911.15 & 0.675 & 0.524 & 0.526 & 0.456 & 1.453 & 1.491 & 2.567 \\
\hline 25 & 1915.10 & 1918.50 & 0.178 & 979.49 & 986.32 & 0.697 & 0.511 & 0.514 & 0.516 & 1.492 & 1.525 & 2.259 \\
\hline 26 & 2102.60 & 2107.40 & 0.228 & 1063.10 & 1070.30 & 0.677 & 0.506 & 0.508 & 0.453 & 1.498 & 1.518 & 1.322 \\
\hline 27 & 2290.20 & 2295.40 & 0.227 & 1153.70 & 1161.90 & 0.711 & 0.504 & 0.506 & 0.480 & 1.489 & 1.506 & 1.169 \\
\hline 28 & 2477.80 & 2483.70 & 0.238 & 1249.90 & 1259.20 & 0.744 & 0.504 & 0.507 & 0.500 & 1.471 & 1.490 & 1.264 \\
\hline 29 & 2665.30 & 2672.20 & 0.259 & 1350.60 & 1361.80 & 0.829 & 0.507 & 0.510 & 0.570 & 1.452 & 1.470 & 1.288 \\
\hline
\end{tabular}




\begin{tabular}{|c|c|c|c|c|c|c|c|c|c|c|c|c|}
\hline \multirow{2}{*}{ section } & \multicolumn{3}{|c|}{ mean } & \multicolumn{3}{|c|}{ mean square error } & \multicolumn{3}{|c|}{ coefficient of variation } & \multicolumn{3}{|c|}{ coefficient of skewness } \\
\hline & measured & simulation & $\begin{array}{l}\text { relative } \\
\text { error(\%) }\end{array}$ & measured & simulation & $\begin{array}{l}\text { relative } \\
\text { error(\%) }\end{array}$ & measured & simulation & $\begin{array}{l}\text { relative } \\
\text { error(\%) }\end{array}$ & measured & simulation & $\begin{array}{l}\text { relative } \\
\text { error(\%) }\end{array}$ \\
\hline 30 & 2852.80 & 2860.10 & 0.256 & 1454.70 & 1467.10 & 0.852 & 0.510 & 0.513 & 0.596 & 1.432 & 1.451 & 1.313 \\
\hline 31 & 3040.40 & 3048.20 & 0.257 & 1561.60 & 1574.90 & 0.852 & 0.514 & 0.517 & 0.596 & 1.414 & 1.433 & 1.323 \\
\hline 32 & 3227.80 & 3236.40 & 0.266 & 1670.70 & 1685.60 & 0.892 & 0.518 & 0.521 & 0.622 & 1.397 & 1.419 & 1.517 \\
\hline 33 & 3073.50 & 3081.40 & 0.257 & 1544.80 & 1558.80 & 0.906 & 0.503 & 0.506 & 0.647 & 1.288 & 1.307 & 1.475 \\
\hline 34 & 2919.20 & 2925.90 & 0.230 & 1422.00 & 1434.20 & 0.858 & 0.487 & 0.490 & 0.620 & 1.162 & 1.176 & 1.188 \\
\hline 35 & 2764.50 & 2770.80 & 0.228 & 1303.50 & 1314.20 & 0.821 & 0.472 & 0.474 & 0.592 & 1.020 & 1.033 & 1.334 \\
\hline 36 & 2610.20 & 2615.40 & 0.199 & 1190.30 & 1199.10 & 0.739 & 0.456 & 0.458 & 0.537 & 0.863 & 0.876 & 1.420 \\
\hline 37 & 2455.70 & 2459.90 & 0.171 & 1084.40 & 1092.20 & 0.719 & 0.442 & 0.444 & 0.550 & 0.702 & 0.714 & 1.719 \\
\hline 38 & 2301.40 & 2305.20 & 0.165 & 987.73 & 993.82 & 0.617 & 0.429 & 0.431 & 0.452 & 0.552 & 0.560 & 1.423 \\
\hline 39 & 2146.80 & 2149.80 & 0.140 & 903.47 & 908.66 & 0.574 & 0.421 & 0.423 & 0.432 & 0.444 & 0.455 & 2.655 \\
\hline 40 & 1992.20 & 1995.80 & 0.181 & 835.46 & 840.29 & 0.578 & 0.419 & 0.421 & 0.396 & 0.411 & 0.423 & 2.935 \\
\hline 41 & 1949.80 & 1952.90 & 0.159 & 802.33 & 806.89 & 0.568 & 0.411 & 0.413 & 0.408 & 0.383 & 0.395 & 3.319 \\
\hline 42 & 1907.20 & 1909.90 & 0.142 & 770.47 & 774.86 & 0.570 & 0.404 & 0.406 & 0.428 & 0.357 & 0.370 & 3.709 \\
\hline 43 & 1864.50 & 1867.20 & 0.145 & 740.04 & 744.17 & 0.558 & 0.397 & 0.399 & 0.418 & 0.335 & 0.348 & 3.971 \\
\hline 44 & 1822.00 & 1824.40 & 0.132 & 711.01 & 714.79 & 0.532 & 0.390 & 0.392 & 0.397 & 0.319 & 0.332 & 4.251 \\
\hline
\end{tabular}




\begin{tabular}{|c|c|c|c|c|c|c|c|c|c|c|c|c|}
\hline \multirow{2}{*}{ section } & \multicolumn{3}{|c|}{ mean } & \multicolumn{3}{|c|}{ mean square error } & \multicolumn{3}{|c|}{ coefficient of variation } & \multicolumn{3}{|c|}{ coefficient of skewness } \\
\hline & measured & simulation & $\begin{array}{l}\text { relative } \\
\text { error(\%) }\end{array}$ & measured & simulation & $\begin{array}{l}\text { relative } \\
\text { error(\%) }\end{array}$ & measured & simulation & $\begin{array}{l}\text { relative } \\
\text { error(\%) }\end{array}$ & measured & simulation & $\begin{array}{l}\text { relative } \\
\text { error(\%) }\end{array}$ \\
\hline 45 & 1779.40 & 1781.90 & 0.140 & 684.01 & 687.32 & 0.484 & 0.384 & 0.386 & 0.346 & 0.311 & 0.323 & 3.810 \\
\hline 46 & 1736.80 & 1739.10 & 0.132 & 658.96 & 662.04 & 0.467 & 0.379 & 0.381 & 0.337 & 0.315 & 0.327 & 3.755 \\
\hline 47 & 1694.20 & 1696.20 & 0.118 & 636.17 & 639.06 & 0.454 & 0.376 & 0.377 & 0.333 & 0.333 & 0.344 & 3.222 \\
\hline 48 & 1651.50 & 1653.50 & 0.121 & 615.77 & 618.64 & 0.466 & 0.373 & 0.374 & 0.346 & 0.367 & 0.380 & 3.519 \\
\hline 49 & 1615.10 & 1617.20 & 0.130 & 596.22 & 598.98 & 0.463 & 0.369 & 0.370 & 0.336 & 0.351 & 0.366 & 4.190 \\
\hline 50 & 1578.80 & 1580.60 & 0.114 & 578.26 & 581.06 & 0.484 & 0.366 & 0.368 & 0.366 & 0.340 & 0.354 & 4.180 \\
\hline 51 & 1542.20 & 1544.20 & 0.130 & 562.02 & 564.70 & 0.477 & 0.364 & 0.366 & 0.348 & 0.333 & 0.346 & 3.740 \\
\hline 52 & 1505.80 & 1507.80 & 0.133 & 547.61 & 550.18 & 0.469 & 0.364 & 0.365 & 0.338 & 0.333 & 0.347 & 4.235 \\
\hline 53 & 1469.20 & 1471.20 & 0.136 & 535.41 & 537.91 & 0.467 & 0.364 & 0.366 & 0.329 & 0.337 & 0.352 & 4.247 \\
\hline 54 & 1432.80 & 1434.90 & 0.147 & 525.45 & 528.19 & 0.521 & 0.367 & 0.368 & 0.379 & 0.347 & 0.363 & 4.626 \\
\hline 55 & 1396.30 & 1398.40 & 0.150 & 517.72 & 520.68 & 0.572 & 0.371 & 0.372 & 0.421 & 0.360 & 0.376 & 4.464 \\
\hline 56 & 1359.80 & 1361.70 & 0.140 & 512.50 & 515.50 & 0.585 & 0.377 & 0.379 & 0.446 & 0.375 & 0.391 & 4.191 \\
\hline
\end{tabular}


It can be seen from Table 4 that the simulated flooding process is close to the statistical parameters of the measured flood process and the relative error is less than 5\%. The simulation results are better and the flood generated by the model basically maintains the statistical characteristics of the measured flood.

According to the above steps, make simulation on the Baise-Nanning flood. It can be got from the calculation that the statistical amount $Q=20.776$. Take significance level $\alpha=0.05$, then $\chi_{\alpha}^{2}=21.0261$ and meets $Q \leq \chi_{\alpha}^{2}$, and the random term $\varepsilon_{t}$ is independent. The model passes independence test can be used for flood simulation by independence test. Calculate the autocorrelation coefficient and $95 \%$ upper and lower allowable limits of the random items of the sample sequence and all autocorrelation coefficients are between $95 \%$ upper and lower allowable limits, so that the random items can be judged to be independent. After counting measure flood process lines, simulating the statistical parameters of various sections of flood process lines, it can be found that the simulated flood sequence are close to the statistical parameters of the measured flood sequence and the relative error is less than $2 \%$, which indicates that the simulated floods maintain the statistical characteristics of the measured floods, and the simulation results are excellent.

\section{Conclusions}

In this paper, the SAR(1) model is used to simulate the flood process of Baise reservoir inflow and Baise-Nanning interval by analyzing the measured flood data.

In the simulation calculation process, the independence and applicability of the model are tested by the autocorrelation coefficient method and the autocorrelation analysis method respectively.

In addition, by comparing characteristic parameters of flood process the simulation generated and various sections of measured flood serials, the relative error of the statistical data (mean, mean square error, coefficient of variation and skewness coefficient) of each section is less than $5 \%$, and the coincidence degree is relatively high, which indicates sufficiently that it is reasonable to use SAR(1) model to simulate the inflow flood of Baise reservoir flood and Baise-Nanning interval.

\section{Acknowledgements}

This work was financially supported by the National Natural Science Foundation of China (51369005).

\section{References}

[1] DING Jing, DENG Yuren, HOU Yu, et al. Advances in Water Science, 1992, 3(1): 45-52. (In Chinese)

[2] YUAN Peng, WANG Wensheng, DING Jing. Journal of Sichuan University: Engineering Science Edition, 2000, 32(1): 82-86. (In Chinese)

[3] WANG Wensheng, YUAN Peng, DING Jing. Journal of Hydraulic Engineering, 2000, 31(11): 43-48. (In Chinese)

[4] XIAO Yi, GUO Shenglian, XIONG Lihua, et al. Journal of Sichuan University: Engineering Science Edition, 2007, 39(2): 55-60. (In Chinese)

[5] ZHANG Tao, ZHAO Chunwei, LUO Wensheng. Engineering Journal of Wuhan University, 2008, 41(4): 1-4. (In Chinese)

[6] WANG Wensheng, JIN Juliang, LI Yueqing, et al: Hydrological water resources stochastic simulation technology (Sichuan university press, Chengdu 2007). (In Chinese)

[7] ZHOU Yanlai, GUO Shenglian, LI Tianyuan, et al. Engineering Journal of Wuhan University, 2013, 46(2): 137-142. (In Chinese) 